\title{
Notas para una ontología de la comunicación II: sobre las "Materialidades de la comunicación"1
}

Eduardo Andrés Vizer²

DOI: 10.5294/pacla.2018.21.2.12

Para citar este artículo / to reference this article / para citar este artigo Vizer, E.A. (2018) Notas para una ontología de la comunicación II: sobre las "Materialidades de la Comunicación". Palabra Clave, 21(2), 553-592. D0I: 10.5294/pacla.2018.21.2.12

\section{Resumen}

Este artículo intenta promover un "giro epistemológico" en las reflexiones teóricas que se realizan sobre las teorías de la comunicación. Aborda perspectivas y problemas que para los lectores y especialistas de la comunicación, en el ámbito de la producción teórica hispanohablante y portuguesa, son poco considerados o tomados en cuenta. Los largos años de investigación empírica y reflexión sobre las teorías de la comunicación rara vez han expandido el campo de pensamiento hacia perspectivas teóricas que incluyan un basamento ontológico sobre las complejidades y la multidimensionalidad de los procesos de comunicación. La escuela de las materialidades de la comunicación aporta una mirada muy importante en la formación de los estudiantes de Comunicación y en las reflexiones para la construcción de teoría sobre el campo. Se presenta un esquema de abordaje tridimensional acerca de los procesos de referencia en la comunicación.

\section{Palabras clave}

Ontología; teorías de la comunicación; materialidades de la comunicación; modelo de referenciación (Fuente: Tesauro de la Unesco).

1 Versión modificada del original publicado en el libro Comunicación, campo(s), teorías y problemas: una perspectiva internacional (Salamanca: Comunicación Social, 2016).

2 orcid.org/0000-0002-1321-8370. Universidad de Buenos Aires, Argentina. 


\section{Notes for an Ontology \\ of Communication II: On the "Materialities of Communication"}

\section{Abstract}

This paper aims to encourage an "epistemological turn" in the theoretical reflections on the theories of communication. It addresses issues and perspectives that, according to the readers and to communication specialists, are little considered or taken into account in the field of theoretical production in Spanish and Portuguese. The long years of empirical research and reflection about the theories of communication have rarely expanded the field of thought towards theoretical perspectives including an ontological foundation about the complexities and multidimensionality of communication processes. The school of materialities of communication provides a very important perspective about the training of Communication students and about the reflections for the construction of theory on the field. The article presents a three-dimensional approach to reference processes in communication.

\section{Keywords}

Ontology; communication theories; materialities of communication; referencing model (Source: Unesco Thesaurus). 


\section{Notas para uma ontologia da comunicação II: sobre as "Materialidades da Comunicação"}

\section{Resumo}

Este artigo tenta promover um "giro epistemológico" nas reflexões teóricas que se realizam sobre as teorias da comunicação. Aborda perspectivas e problemas que para os leitores e especialistas da comunicação, no âmbito da produção teórica hispano falante e portuguesa, são pouco considerados ou levados em conta. Os longos anos de pesquisa empírica e reflexão sobre as teorias da comunicação rara vez têm expandido o campo de pensamento dirigido a perspectivas teóricas que incluam fundamentos ontológicos sobre as complexidades e a multidimensionalidade dos processos de comunicação. A escola das materialidades da comunicação proporciona uma visão muito importante na formação dos estudantes de Comunicação e nas reflexões para a construção de teoria sobre o campo. Apresenta-se um esquema de abordagem tridimensional sobre os processos de referência na comunicação.

\section{Palavras-chave}

Ontologia; teorias da comunicação; materialidades da comunicação; modelo de referência (Fonte: Tesauro da Unesco). 


\section{Comunicación y ontología}

Para una ontología relacional, podríamos decir que todo lo que "es", es en relación. Las nociones centrales, desde esta perspectiva, son configuracióny estructura; ya para el abordaje cualitativo de la ontología, las nociones centrales son forma y cualidad (a su vez definidas como descriptiva o determinante, asociada a causalidad). Cuando nos preguntamos por las cualidades de un proceso de comunicación, nos preguntamos por su "configuración y su estructura", por sus "formas y sus cualidades", y en la literatura comunicacional vemos casi siempre interés teórico y práctico por las cualidades descriptivas por sobre las determinaciones, mientras que en las ciencias "nomotéticas" siempre existe la presencia del modelo ideal de la explicación y la determinación. Y las razones para esta diferencia epistemológica se hallan en la concepción ontológica de base que existe sobre la comunicación como un proceso que puede ser analizado, descrito e interpretado, pero difícil o excepcionalmente "explicado" científicamente desde el propio campo de la comunicación o la información. Casi siempre se introducen en la explicación hipótesis de naturaleza exterior a los procesos de la propia discursividad entendida como lenguaje en un sentido restringido, introduciendo implícitamente en los análisis de la comunicación hipótesis sobre procesos originarios de la psicología, la biología, la cultura, etc. No tanto sucede con la información, sobre la que siempre existe una impronta ingenieril operativa como sustento epistemológico, ya sea que se la proyecte y aplique hacia procesos de la física o la biología de los seres vivos. Estas distinciones a la vez ontológicas y epistemológicas no se hallan prácticamente en ninguna literatura sobre la comunicación en sentido estricto, ni de manera explícita ni implícita, pero ya en los estudios sobre los procesos de la mediatización social, o sea, sobre las influencias de las tecnologías, los medios de información y comunicación, la digitalización y las profundas implicaciones sobre las sociedades y las culturas humanas, las "cuestiones ontológica y antropológica" se deben plantear con toda seriedad y profundidad. La comunicación mediatizada, si bien aún puede ser entendida como propiedad de la "naturaleza humana" en un sentido antropológico tradicional, corresponde a un orden de escala y complejidad totalmente nuevo en el desarrollo de los procesos civilizatorios. El signo y el significante de la palabra enunciada por la boca humana o el papel escrito 
no han muerto en el mundo virtual o en las "escrituras" de los lenguajes digitales, pero en cuanto soportes de la comunicación humana se han transfigurado en elementos o "recursos polisémicos". Esto porque dentro de las nuevas dinámicas ecológicas en que nos toca vivir (en especial en las ciudades y en los conglomerados humanos urbanizados) nuestras diferentes ecologías (desde la física, pasando por la social y la simbólica) son sustentadas en la física y la ingeniería de la información.

Hace años, elaboré una definición de la comunicación como la "construcción de sentido sobre los procesos de construcción de sentido”, como una construcción de recursividad teórica sobre las prácticas de comunicación en la vida social o una construcción metacomunicacional sobre la comunicación. Si el signo y el significante han sufrido una transfiguración radical como soportes teóricos de la comunicación, la construcción de discursos sobre el sentido viene sufriendo traducciones, muertes, resurrecciones y una búsqueda casi desesperada por nuevos signos y nuevos valores capaces de poner cierto orden interpretativo en la confusión impuesta por los procesos de mediatización, ya que estos imponen transformaciones revolucionarias en todos los órdenes de la vida humana. Lo que comúnmente se denomina ciencias de la comunicación se compone de una diversidad conceptual enorme de temas y objetos. Son resultante de la multiplicidad de abordajes y miradas sobre la comunicación que ha generado una confusión no resuelta entre campos de estudio, objetos de análisis, metodologías y definiciones pasibles de delimitar una especificidad conceptual mínima pero indispensable para la elaboración de un andamiaje intelectual capaz de promover una práctica de construcción de conocimiento con cierto grado de "normalización", y con rasgos de especificidad que permitan su reconocimiento como "ciencia". De hecho, la historia de las ciencias nos muestra que la construcción de un campo de conocimiento científico requiere ciertos núcleos conceptuales, reglas o convenciones asumidas implícitamente entre una comunidad de personas interesadas en desarrollar una serie de cuestiones problema compartidas o coincidentes. Este no ha sido el caso en la historia aún relativamente breve de la comunicación. La multiplicidad de cuestiones y problemas abordados seguramente ha sido mayor a la de otras ciencias sociales. Creemos que esto no es solo un indicador de la complejidad 
y cantidad de objetos que se ofrecen para abordar su estudio, sino de las complicaciones que presenta un campo de conocimiento que se ve obligado a lidiar con varios y diferentes "niveles de realidad", como se decía en la década de 1960: de los procesos mentales y lingüísticos a los sociales, de los políticos a los históricos, tecnológicos y económicos.

Hoy en día, ya nadie cree que el edificio del conocimiento se construye brick by brick (o ladrillo a ladrillo) y que los avances se dan forzosamente acumulando experiencias limitadas. Y tampoco existen acuerdos amplios y compartidos sobre una naturaleza específica de los procesos comunicacionales. Por el contrario, ni hay acuerdo generalizado sobre si el campo debe constituirse en una disciplina, una interdisciplina o una "transdisciplina", ni aun sobre su cientificidad en sentido estricto. Donde parece haber cierto acuerdo compartido es sobre la esencia intrínsecamente semiótica de los procesos de comunicación. Sobre su naturaleza de "puente" entre los procesos de la subjetividad humana y los contextos del "afuera", ya sea el contexto social, el tecnológico, cultural, económico o político.

La hipótesis sobre la naturaleza "constructiva" de la comunicación ${ }^{3}$ en la conformación permanente de las subjetividades constituye posiblemente la afirmación epistemológica más fuerte para marcar una especificidad para el campo. E incidiendo implícitamente sobre el "afuera", como en una moneda de dos caras, también sobre los procesos de construcción de modificación o de reconstrucción- de los múltiples contextos de vida social a partir de las interacciones y los procesos "internos" que los individuos pueden expresar y "exteriorizar". Es a este proceso de modificación y adecuación del afuera al que en otros escritos denominé un "cultivo" del contexto por parte de los individuos y de sus interacciones mutuas y con el medio circundante, ya sea este físico, material o estrictamente humano. Estos son los procesos que la literatura comunicacional y sociológica ha denominado mundos de la vida, donde las fronteras entre el adentro y el afuera, lo físico y lo psíquico, el mundo personal y el colectivo, el mundo material y el cultural se funden y construyen un "mundo de la vida emergente", en

3 La comunicación como un proceso de construcción de la vida social ha sido un postulado fuerte y aún vigente a partir de los trabajos de Berger y Luckmann en la década de 1960. 
un sentido ontológicamente renovado. En el mundo de la comunicación, el adentro y el afuera, el individuo y sus contextos, el lenguaje y la acción, los símbolos y los procesos cognitivos se constituyen mutuamente y hacen prácticamente indiscernible separar las diferentes instancias de un proceso que conforma una estructura de origen, a la vez antropológica, cultural, psíquica y tecnológica (sobredeterminada por las tecnologías de la información y de la comunicación [TIC]). Una estructura de vida humana emergente, a la vez compleja y evanescente para la ciencia normal. ¿Cómo abordar la complejidad de esta nueva forma de vida civilizada sin hacer reduccionismo? ¿Cuáles pueden ser las nuevas "teorías de medio alcance" que nos permitan contar con una brújula teórica y avanzar en este bosque sin quedar limitados a la visión del árbol que tenemos enfrente?

Varias disciplinas han propuesto brújulas teóricas para alumbrar partes del bosque: la sociología de los medios de comunicación; la psicología de la comunicación, los procesos de recepción y la psicología de las masas; la semiología y la semiótica de los lenguajes; la proxémica y hasta la economía de la información y la comunicación, ${ }^{4}$ donde los medios ocupan una posición intermedia entre la cultura y el poder económico y político. Todas parecen alumbrar aspectos y cuestiones relevantes de lo que se ha convenido en denominar comunicación. ¿No será esta palabra una etiqueta o una convención lingüística para referirnos a un proceso que reúne un conjunto de instancias y procesos ontológicamente diferenciados entre sí? Si este fuera el caso, ¿qué sentido tendría seguir hablando de una disciplina de la comunicación, cuando deberíamos aceptar que el campo se constituye en una multiplicidad de conocimientos y objetos teóricos diversos que tienden a entrecruzarse entre sí solo cuando nos enfrentamos a un problema concreto de investigación o al requerimiento formal de los organismos de financiación a la investigación? Las teorías de la comunicación han operado en general como metáforas o alegorías sobre diferentes miradas hacia

4 "No cabe duda de que, como una esfera de producción cultural, los medios pueden, a primera vista, ser analizados como un único campo o una colección de campos, (cada uno) con un patrón distintivo de prestigio y estatus, así como con sus propios valores. Efectivamente, según Bourdieu, la posición intermedia de los medios entre el polo cultural y el económico del campo cultural más amplio le da un interés particular como campo. Esta sección señala la contribución positiva de la teoría de campo al análisis de los medios y luego identifica una tensión clave en su tratamiento del poder de los medios" (Couldry, 2004, p. 653). 
los procesos y los posibles objetos de la comunicación. Un abordaje hermenéutico de la comunicación — que la limite al "sentido"- es cómo hablar del hogar sin hablar de la casa. Pero solo hablar de los materiales necesarios para hacer una casa sin tomar en cuenta que se está construyendo un hogar (o un hospital, una cárcel o una escuela) es como hablar solo del sonido de las palabras o del sonido del violín, pero no de las melodías. La comunicación necesariamente implica ambas: el sonido y la melodía, la casa y el hogar. El "efecto de presencia" de una casa no basta para entender el "efecto de sentido" que significa un hogar. La presencia de un significante no es suficiente para entender un significado, pero este sin un soporte significante o una forma de "presencia" física no es posible, no tiene significación. La materia en que se inscribe un significante "significa".

\section{Ciencias de la comunicación, ciencias de la vida y las "materialidades de la comunicación"}

Estas cuestiones nos llevan a pensar en el ejemplo que presentan las "ciencias de la vida", las que configuran un conjunto de disciplinas y saberes a los que se considera asociados al estudio de los procesos en los sistemas vivientes, o sea, los organismos vivos. Puede parecer chocante la comparación que proponemos entre ciencias de la vida y las de la comunicación, pero realmente encontramos una gran equivalencia y puntos de interés en común entre ambas. Las primeras reúnen un conjunto enorme y complejo de objetos de estudio y al mismo tiempo proponen un universo filosófico común, además del interés teórico y empírico por diferentes formas y estructuras vivientes. ¿Qué condiciones geológicas, físicas y químicas han sido necesarias para hacer posible el surgimiento de la vida? ¿Cuáles son las propiedades y condiciones del entorno y del propio sistema vivo que hacen posible su supervivencia y crecimiento? Si reemplazamos "ciencias de la vida" por ciencias de la información o de la comunicación y nos preguntamos por las condiciones históricas y los orígenes filogenéticos de la capacidad del cerebro animal y el humano para procesar información, generar lenguaje y desarrollar capacidad semiótica, estaremos explícitamente asociando ambos conjuntos de ciencias y llevándolas hacia posibles convergencias e interdependencias mutuas. El concepto de información ha cumplido 
precisamente un papel estratégico en establecer puentes teóricos (a veces como una mera metáfora) y comparaciones entre procesos físicos, biológicos, técnicos y mentales (como la tesis - ahora prácticamente en desuso- sobre el cerebro como mero procesador de información, trasladado a la inteligencia artificial). En otras palabras, se ha abierto la posibilidad de superar la barrera que parecía infranqueable entre las ciencias biológicas, las sociales y las cognitivas, abriendo un campo de exploración enormemente fructífero y promisor, en especial teniendo en cuenta que muchos de los avances científicos se realizan en el trabajo sobre cuestiones de frontera entre disciplinas diversas. ${ }^{5}$ Así como la sociología ha recurrido a analogías (a veces peligrosas) entre sistemas biológicos y sistemas sociales, los primeros estudios sobre los medios de comunicación se han hecho aplicando presupuestos teóricos y analogías con procesos sociológicos y con los modelos matemáticos de la comunicación y posteriormente con modelos originados en la teoría de los sistemas. La condición humana es inseparable de la evolución de sus capacidades semióticas, y estas lo son de sus condiciones de vida. El conocimiento sobre los sistemas vivientes requiere inevitablemente conocer sus capacidades y dispositivos específicos para establecer intercambios y el "procesamiento de información" con su entorno. Y el ser humano se ha desarrollado, sobrevivido e impuesto sobre condiciones ambientales desfavorables gracias, sobre todo, a su potencialidad semiótica.

¿Nadie puede afirmar que no existe algo más profundo en común entre la comunicación humana y los procesos biológicos en los seres vivos o las conversaciones entre dos personas en la calle o las señales que llegan a las pantallas de nuestras computadoras, celulares y hasta los chips que algunos individuos se insertan en sus cuerpos? ¿Qué es lo que podemos considerar, en efecto, una esencia específica que existe en ese proceso, ese hecho en común? ¿No sería sobre todo ese proceso el que epistemológica y teóricamente nos interesa conocer? ¿Existe una ontología propia

5 "No existe ciencia del discurso considerado en sí mismo; las propiedades formales de las obras (o los textos) revelan su sentido solamente cuando son referidas a las condiciones sociales de su producción” (Bourdieu, 1996, p. 129). "Inspeccionada en todos sus detalles de funcionamiento, la relación social que el dispositivo de comunicación pone en juego —emisión, recepción, escritura, lectura, habla, escucha - se limita a ofrecer muy pocos esclarecimientos sobre su razón social; y es por esto que, a diferencia de la mayoría de las relaciones sociales, ella solamente existe cuando se halla inserta en otras relaciones" (La Haye, 1984, pp. 41-42, citado por Vizer y Carvalho, 2012). 
que debemos explorar? ¿Una ontología de la comunicación tal como consideramos que existe una ontología de la vida? ¿Una ontología que forzosamente nos lleva a su historia, a sus orígenes antropológicos, biológicos y culturales? ¿Una ontología de la comunicación constituye una dimensión central para la comprensión de la vida social de la que se ocupa la sociología, la antropología o la psicología?

¿No convendría abordar la comunicación humana como un proceso de emergencia y organización de ciertas estructuras vivientes y sus procesos concomitantes, en cuanto el hombre es un animal biológico e histórico, dependiente de la naturaleza física, social y cultural y, además, un explorador y constructor permanente de estructuras de sentido? Una emergencia evolutiva que solo se hizo posible merced a las funciones y la capacidad semiótica del ser humano. Una emergencia biológica e histórica que solo ha sido posible por la capacidad del cerebro y de las redes neuronales para manipular símbolos, lo cual, a su vez, condicionó durante generaciones la evolución de estructuras cerebrales y los procesos mentales que emergen de las interrelaciones de los individuos con su medio físico y social, movilizando y provocando una dinámica biopsíquica, social y cultural, en la que el ser humano nace y evoluciona. Por último, ha sido esta emergencia de funciones semióticas en el animal humano la que lo ha llevado a construir (cultivar) el medio ambiente en el que ha vivido. $\mathrm{Y}$ a su vez, a cultivar una vida social y cultural cada vez más compleja, ahora integrada físicamente a través de nuevas tecnologías en red.

No es una exageración sospechar que tal vez se encuentre un basamento teórico para los estudios de la evolución en el desarrollo de investigaciones sobre la naturaleza de las funciones semióticas que el ser humano ha desarrollado, en la capacidad del cerebro para crear, manipular y compartir símbolos colectivamente. Seguramente, es esta capacidad del cerebro para procesar estímulos, señales e información la que ha permitido la emergencia de lo que llamamos mente, y su dinámica a la vez material y simbólica. Es hoy una tesis fuerte la hipótesis de que esta dinámica a la vez física, biológica y cultural que constituye al ser humano le ha permitido vivir en una ontología propia y diferenciada (un Umwelt, un entorno condicionado por 
los hombres y por el medio físico). Un organismo que sobrevive mediante una permanente exploración de signos, señales, lenguajes, símbolos, imágenes y también imaginarios que constituyen la vida en sociedad (equivalente a lo que en los términos de la tradición de los estudios de comunicación se ha denominado mundos de la vida), donde se combinan el colectivo social con lo físico material, lo simbólico y lo imaginario, integrados todos en la formación de la identidad personal.

Para el investigador canadiense Robert Logan, este proceso complejo se puede resumir en una ecuación que propone la siguiente formulación para la articulación entre el lenguaje, la cultura y el cerebro:

$$
\text { Mente }=\text { cerebro }+ \text { lenguaje }+ \text { cultura } .
$$

"Considerando que el lenguaje es un artefacto cultural, tiene sentido pensar que otros artefactos y procesos culturales también contribuirían para la forma como la mente humana es construida" (Logan, 2012, p. 101).

¿Cómo no reconocer que estas complejas formaciones biopsicosociales a lo largo de la evolución humana han conformado un orden nuevo y emergente en la vida de la especie, y que convendría estudiarlas como "ontologías emergentes de la vida y la comunicación”, reuniendo a un mismo tiempo la vida cotidiana con las condiciones necesarias para una ciencia de la semiosis? No podemos olvidar que los procesos de semiosis han surgido evolutivamente en la historia biológica, social y cultural de la especie. Una historia que desde un principio fue condicionando las posibilidades de creación de un sistema viviente en el que se desarrolló el ser humano dentro de un orden ecológico particular y evolutivo.

Entiendo que una hipótesis tan general y amplia sobre la comunicación obligaría a una reinterpretación de las teorías micro-, meso- y macrocomunicacionales. Y acá es donde han aparecido en las dos últimas décadas teorías como las que presenta la escuela de las materialities of communication, donde el acento de las investigaciones se halla menos asociado a las teorías hermenéuticas sobre la formación del sentido, y más sobre los "acoples" 
entre los sistemas de sentido y los sistemas que no requieren necesariamente un "sujeto observador externo", tal como presuponen las ciencias físiconaturales. En otras palabras, una valoración mayor de los procesos físicos y las materialidades en los que se asienta la formación del sentido, no solo lo que una palabra humana significa, sino "cómo" es generada y materializada en ciertos contextos. No tanto en lo que los medios "dicen", sino cómo y en qué condiciones son dichas (condiciones materiales y sociales propias de los medios físicos de expresión). McLuhan vuelve al tablero intelectual por sus propios fueros, ahora interesantemente asociado a Niklas Luhmann y a Ulrich Gumbrecht.

Es el propio Gumbrecht el que esclarece la posición de la teoría de las materialidades en relación con otros posibles constructos teóricos:

Nuestro esfuerzo para circunscribir las "materialidades de la comunicación" como un campo de investigación y reflexión no cuestiona necesariamente la legitimidad epistemológica de otras posiciones teóricas contemporáneas, ni implica cualquier pretensión de cubrir la totalidad del espacio que las ciencias humanas tradicionalmente han ocupado (1994: 396). (Felinto, 2006, p. 43)

La nueva revalorización de las condiciones materiales que permiten y condicionan la formación de los procesos de información y comunicación llevan indefectiblemente a un abordaje de la comunicación, ya no solo como proceso de sentido (subjetivo y abstracto), sino como proceso a la vez material e inmaterial, físico y mental, ecológico y de enorme "fuerza ontológica”. Como señalaba al inicio de este trabajo sobre una ontología de la comunicación, "nos preguntamos por las 'cualidades' de un proceso de comunicación, nos preguntamos por su "configuración y su estructura", por sus "formas y sus cualidades". La comunicación puede y debe afirmar su validez ontológica, como un espacio y una estructura (esencia de la información) y como un constructor de temporalidad y, en consecuencia, también de la intersubjetividad humana (comunicación).

Hace varios años, pensé, instigante y seguramente fructífera, una asociación entre los procesos de construcción de sentido - proceso inmaterial- con las nociones de tiempo y espacio físico material. Esto en función 
de una hipótesis de articulación entre estos últimos procesos materiales y los inmateriales, propios de la construcción de sentido en la información y la comunicación (espacio y tiempo son comúnmente considerados propios de las ciencias físicas y ajenas a la comunicación). Tiempo, espacio y sentido articulados así en una ecuación de naturaleza ontológica.

1. Se puede concebir la información como "creación" de un espacio lógico y topológico estructurado entre tres elementos o vectores: a) el "texto" o mensaje material, o sea, las marcas físicas del "medio transportador"; b) la realidad externa u objeto que es "referido" en el mensaje, que se "traduce", construye y reconstruye por medio del trabajo mental (o una inteligencia artificial computacional) reconociendo e "interpretando" un mensaje a través de las marcas, los signos y los trazos físicos; y3) el "intérprete" humano que construye sentido a partir de las relaciones entre las tres instancias o elementos. Podemos considerar que las relaciones topológicas entre las tres instancias estructuran un "espacio", una ontología emergente pasible de ser expresada o traducida a gráficos. Es la articulación temporal entre las tres instancias la que hace posible la información y la comunicación: la materialidad física del medio, la materialidad de los signos y la inmaterialidad del código lingüístico y sus reglas y, finalmente, la " $n$ materialidad del proceso de interpretación (una inmaterialidad que para la inteligencia artificial y para las ciencias cognitivas pronto será totalmente material y cognoscible científicamente). Respecto de los procesos de información, amén de conformar un espacio lógico y topológico tanto material como inmaterial, requieren la técnica y las tecnologías desarrolladas desde lejanos tiempos para ordenar operaciones, actos y decisiones en todas las sociedades humanas.

Tenemos así una asociación (aún incipientemente formulada) entre los conceptos de espacio, topología y ontología, técnica e información y medio y trabajo de interpretación en el tiempo.

2. Se puede concebir la comunicación también como un proceso de generación de tiempo o como una emergencia resultante del proceso de 
entrecruzamiento entre los tres elementos del "espacio-información". Esta emergencia, este proceso de relacionamiento permanente y dinámico de "trabajo" entre los tres elementos del espacio-información para un intérprete genera distinciones que proporcionan la experiencia y la vivencia del tiempo, más allá del proceso de interpretación en sí mismo. En otras palabras, la infocomunicación, por un lado, como un proceso de construcción y diseño de espacios materiales sobre el que se construyen espacios lógicos de significación (equivalente a "significantes" o estructuras de información); y por otro, la infocomunicación como proceso de construcción y traducción de significados. Proceso de interpretación que para los agentes involucrados implica asumir una temporalidad, una duración del tiempo de la comunicación que nos implica como humanos históricos. La duration ontológica del presente en el que todos vivimos y dentro del cual el pasado y el futuro dejen de ser meras figuras de lenguaje. Cada uno de nosotros "es" su duration, y la comunicación es seguramente la actividad humana ontológicamente más vital para la construcción del presente y de la identidad.

Pondré un ejemplo específico de articulación de estos conceptos en el mundo real de la cultura de la información en que las tecnologías están reconfigurando todos los órdenes de la realidad. Por ejemplo, internet de las cosas tiende a conectar cada vez más objetos, personas y procesos por medio de nodos receptores, tras lo cual conforma un horizonte de futuro (propuesto por tecnólogos y empresarios), en que la conectividad llegará a ser total e ilimitada. Todo el mundo conectado en un solo espacio a la vez real y virtual. Un espacio topológico único definido por la conectividad total según dispositivos, programas y algoritmos matemáticos. Los operadores de los procesos que sustentan todo el sistema no precisan de un "sentido" adjudicado por seres humanos (o sea, de un "observador hermenéutico"), sino de programas y dispositivos capaces de aprender a desarrollar una inteligencia artificial autónoma. ${ }^{6}$

6 Lo que nos preocupa como seres humanos es el miedo a la precariedad y a la irrelevancia (en el trabajo, en el amor o en la política). La sospecha creciente de que un mundo de la información torne irrelevantes una enorme cantidad de empleos y profesiones y valores fundamentales de la democracia es seguramente una de las razones centrales para el crecimiento exponencial del uso de los medios y las redes de comunicación como forma de expresión personal. 
Como construir conocimiento reconocible por la comunidad científica exige un recorte de los hechos por ser estudiados, una delimitación de carácter ontológico sobre el universo real por ser abordado, los procesos de la comunicación —entendidos en su complejidad real— difícilmente han respondido hasta ahora a los criterios que exigen las ciencias naturales, $y$ tampoco estrictamente a las ciencias sociales. La ciencia exige un alto grado de materialidad, objetividad y comprobabilidad (y en lo posible refutabilidad) para sus hipótesis y teorías. Y esto es, precisamente, lo que pueden aportar disciplinas y miradas diversas que ayudan a contextualizar los procesos de comunicación y su carácter a la vez objetivo y subjetivo, social y cultural-simbólico. ${ }^{7} \mathrm{Y}$ al mismo tiempo permite investigar su materialidad física: lenguajes, imágenes y textos, su naturaleza a la vez cognitiva, sensorial, sensible y emocional, tanto subjetiva como objetiva, individual y colectiva. Tomamos en consideración la materialidad ontológica de los hechos y los acontecimientos sociales, las tecnologías y las producciones humanas - que la tradición antropológica subdividió en cultura material y cultura simbólica - tanto como los procesos de naturaleza biológica y mental que abordan las ciencias cognitivas. La comunicación se halla en todas estas manifestaciones y hace difícil señalar unas sobre otras, ya que todas hacen la construcción de la vida humana (los mundos de la vida), tal como la concebimos, una distinción propia del género humano. La naturaleza evanescente de la comunicación como un proceso de mediación permanente dificulta definirla y circunscribirla empírica y ontológicamente. Por eso, diferentes disciplinas que abordan procesos de comunicación se adjudican la preeminencia de uno u otro abordaje: desde la semiótica a la ingeniería, de la antropología a las ciencias cognitivas. La búsqueda de una definición ontológica de su objeto de conocimiento ayudaría a dar cierta tranquilidad mental y un asidero de precaria materialidad a los investigadores de la comunicación.

Lo que subyace es un miedo profundo a la pérdida de la identidad y la autonomía. Como la identidad se construye según el otro, los dispositivos que configuran el mundo de los objetos desde la infancia tienden a tomar el lugar del otro humano y reemplazarlo por aparatos, dispositivos, robots y avatares (virtuales o no).

7 Es interesante notar que donde se han hallado algunas de las experiencias más fructíferas en la investigación de la comunicación es, precisamente, en áreas de frontera entre disciplinas diferentes como la psicología, la sociología, la política o la economía. 
Para De Saussure (2008) cien años atrás, el sistema de la lengua constituyó una nueva ciencia del lenguaje, así como unas décadas antes la filosofía y la lógica habían constituido las bases epistemológicas del conocimiento sobre los procesos de la semiosis para Peirce (1999). De Saussure - o los alumnos que reunieron sus trabajos - dio origen a una nueva disciplina del lenguaje que lo concebía bajo dos perspectivas: la disciplinaria del "sistema de la lengua" (la lange) y otra asociada a sus prácticas, a una inabordable e incierta ciencia de la parole, la palabra hablada, mientras Peirce y sus herederos intelectuales siguieron otro camino. La semiótica y la teoría de los signos no debían renunciar a sus orígenes filosóficos ni a la amplitud y riqueza de un abordaje más próximo a una reflexión lógica sobre la ontología de la semiosis. Para la escuela francesa y continental, el modelo ideal de conocimiento sobre el lenguaje constituyó el paradigma de la disciplina científica; en cambio, para la norteamericana, una ciencia de los signos debía conservar su asociación histórica con la filosofía, la lógica y la pragmática. Para Peirce, el signo no es una "entidad", un objeto monolítico, sino un complejo de relaciones triádicas con poder de autogeneración como un proceso en continuidad temporal, como devenir. La semiosis es una relación de momentos dentro de un proceso recursivo e ininterrumpido, lo cual guarda en relación con la semiología de De Saussure cierta asociación con la noción de parole, más que con la del sistema de la lange, precisamente la que el estudioso suizo consideraba un objeto de estudio científico poco viable, y no sujeto a reglas. Esta postura epistemológica originalmente confinó la semiología histórica continental al estudio de las reglas y las estructuras y no a los procesos y las conversaciones en la realidad social, lo cual sí hizo la escuela de Chicago desde su comienzo, donde la pragmática de la comunicación cobró un lugar central, precisamente al revés de lo que implícitamente rechazaba De Saussure por considerarlo inabordable científicamente.

Si durante algunas décadas del siglo XX la pujanza universal de los medios de comunicación permitió la elaboración de modelos teóricos que respondían más o menos aceptablemente a las cuestiones planteadas por el cine, la radio y la televisión analógicos como procesos unidireccionales entre un emisor y una multitud de receptores "pasivos", la digitalización y 
los usos de nuevas tecnologías están haciendo explotar y multiplicar exponencialmente las intersecciones e interdependencias entre la tecnología, la economía, la política y la cultura. La presente cultura tecnológica ha transformado desde la infraestructura física de las ciudades sometiéndolas a un control inteligente y permanente merced a la informatización (como el llamado internet de las cosas que interconecta los objetos de una "ciudad inteligente"), pasando por las incesantes transformaciones en la economía productiva, hasta la producción de cambios revolucionarios en las propias prácticas sociotécnicas y culturales de los seres humanos que las habitan.

En esta ecología material de cambios objetivos permanentes, de innovaciones técnicas que inducen a una aceleración creciente del tiempo y la reducción del espacio físico, en forma paralela se viene multiplicando la generación de nuevos espacios virtuales. Se han transformado totalmente, no solo nuestras ecologías físicas, sino las concepciones y teorías con las que pretendimos darles sentido. Las teorías han quedado paulatinamente desfasadas de las cuestiones y los problemas para las que fueron pensadas y construidas. Las creencias establecidas pierden su función de interpretación y adjudicación de sentido para las realidades sociales, económicas y culturales, dejan de tener la funcionalidad estratégica para dirigir, orientar y regular procesos de acción social, desde lo individual a lo colectivo. En términos sociológicos, indicaríamos que surge la anomia, una degradación de las funciones de autorregulación de los sistemas (económicos, judiciales, de gobierno, de organización de los saberes). En términos cibernéticos, señalaríamos que surge una entropía creciente en las formas de organizar conjuntos de órdenes sociales. Los sistemas técnicos de organización económica, social y política, en sus aspectos materiales como simbólicos, los que teóricamente debían acompañar los hechos y las prácticas de producción, de información y de comunicación en forma permanente, dejan de ser válidos para el desarrollo y mantenimiento de cada orden social. ${ }^{8}$ Las ideas, las estrategias, los

8 Las innovaciones técnicas, por ejemplo, no surgen y son apropiadas solo como actos de inspiración individual, sino a partir de cambios y transformaciones en las topologías (u ontologías) sociosimbólicas y materiales en las que se integra a la nueva tecnología o al nuevo modo de acción sociotécnica sobre procesos y organizaciones complejas, donde los "actantes" (según la teoría actor-red de Latour [2005]) conforman un sistema multidimensional a la vez material y simbólico, humano y no humano, un complejo de actantes reales tanto de orden físico, material y social como simbólico y cultural. El método de socioanálisis, que he desarrollado para el estudio de procesos organiza- 
conocimientos y las teorías precedentes, elaboradas, aprendidas o adaptadas a situaciones y tópicos anteriores, no logran generar y sostener un conocimiento capaz de elaborar "islas de orden" y una certidumbre racional. Unos años atrás hubiéramos dicho que epistemológicamente se produce un quiebre de paradigmas, y una efervescencia de modelos teóricos sustentados como metáforas que pretenden tener mayor legitimidad que la que realmente merecen en cuanto hipótesis científicas.

Al fin y al cabo, cuando se habla de los medios, se está pensando en subsistemas sociotécnicos que operan como mediadores dentro de los sistemas sociales, y cuando se habla de los efectos de la recepción sobre los individuos y los grupos, se está hablando del hombre (o de los seres humanos) como sistemas biopsíquicos.

\section{La transversalidad de la comunicación}

La comunicación como un dios omnipresente parece estar en todos lados y en ninguno. Hasta parece más fácil hablar de lo que la comunicación no es, de su debilidad teórica frente a otros campos de conocimiento o frente a disciplinas recientes, o de sus fracasos en establecer una "comunicación efectiva”, o el entendimiento en la vida política y cotidiana. Es más fácil hablar de sus flaquezas que de sus logros en esclarecer la naturaleza efectiva de las prácticas de comunicación, de su "ser social" como proceso de creación de discursos y sentidos, o de su naturaleza creadora de lazos sociales. Se piensa la comunicación como una práctica estratégica de planificación de la intervención en instituciones, comunidades, la generación de universos culturales y su efectividad simbólica. Hubo hasta definiciones de la comunicación como ciencia de los márgenes, como área desteñida del saber entre las ciencias, como una disciplina de cruce entre las humanidades y las tecnologías o entre las ciencias cognitivas y las ingenierías informacionales. Pero, seguramente, la asociación más fuerte se ha establecido con las ciencias sociales, de una importancia fundamental y aportes que muchas veces no han sido reconocidos. Acaso, la estrategia fundamental para abordar la

cionales y comunidades, plantea precisamente la posibilidad de analizar los impactos, las condiciones y los efectos sistémicos que se producen con la inclusión de nuevos dispositivos y tecnologías en comunidades e instituciones como fábricas, hospitales, comunidades rurales, escuelas, y todo tipo de organizaciones. 
multiplicidad de campos de conocimiento y disciplinas que puedan configurar un campo de la comunicación diferenciado y con identidad propia consiste en profundizar en las articulaciones e interrelaciones que definen la comunicación con la marca de una inquietante "transversalidad". Si la perspectiva transversal ${ }^{9}$ puede llevar la "visión horizontal" hacia una amplitud temática de múltiples cuestiones, problemas y objetos de estudio (Deleuze y Guattari, 1997), la "verticalidad” deberá aportar a una perspectiva de profundización conceptual en cada tema. Paulatinamente, podría ir configurándose una convergencia de temas, de objetos y de abordajes compartidos hacia un núcleo de cuestiones interrelacionadas y hasta tal vez definitorias de una problemática común. Podemos mencionar como ejemplos de conjuntos de cuestiones compartidas en diferentes abordajes de la comunicación la problemática del sentido, los formatos de diferentes lenguajes, las cuestiones del discurso, la cognición, las prácticas cotidianas como procesos semióticos y de construcción de sentido, las tecnologías, la cultura, la organización de instituciones y comunidades y hasta el mundo psíquico, todos como procesos de emergencia y producción de sentido.

En La trama (in) visible de la vida social: comunicación, sentido y realidad (2003, 2006, 2012), definí la comunicación como el estudio recursivo de los procesos de construcción de sentido sobre los procesos de construcción de sentido en la vida social, teniendo como una característica fundamental la recursividad de los procesos de comunicación, la necesidad de "funcionar" articulando diferentes niveles de organización del lenguaje. Niveles que funcionan permanentemente como bucles que se arman de manera referencial, o sea, en relaciones de referencia lógica unos de otros. Esta ha sido la característica que los teóricos de la comunicación han denominado muy adecuadamente metacomunicación, proceso sin el cual las relaciones humanas, la organización y la construcción de sentido serían del

9 “(Deleuze \& Guattari, 1997) ubican a la transversalidad como un medio de escapar a las visiones verticales y jerarquizadas de organización de los saberes; y/o a las visiones horizontales de masificación y agrupación genérica de los actores y agentes del escenario de producción de saberes. De esta forma, podemos decir que en el escenario epistemológico actual del campo de la Comunicación, la cuestión digital en sus diferentes aspectos puede asumir un carácter transversal de tal forma que atraviese los dos sentidos clásicamente estructurados: horizontalmente a todos los sub-campos y/o especialidades y verticalmente en cada proceso, soporte y praxis. La visión transversal puede llevar la horizontalidad a una perspectiva de amplitud temática y la verticalidad a una perspectiva de profundidad en cada tema" (Saad Corrêa, 2015). 
todo imposibles. A su vez, las teorías de la comunicación serían así consideradas como una construcción de metáforas inferenciales sobre los procesos de construcción de sentido. La comunicación se halla explícita o implícitamente asociada a los procesos de interpretación, y es precisamente la construcción de metáforas ${ }^{10}$ e inferencias la que ayuda a referenciar y sintetizar ideas, proposiciones, planes de acción, propuestas y acuerdos sobre situaciones o sobre conflictos y visiones de mundo, o bien contrapuestas, o bien compartidas.

Tanto las nociones de lenguaje como la de sentido presentan una centralidad absolutamente fundamental para la problemática de la comunicación. Nos remiten directamente a las preguntas sobre las interrelaciones tanto ontológicas como epistemológicas entre la infinidad de prácticas, tecnologías y soportes de la información y la comunicación social en un sentido "horizontal" como vertical a las cuestiones de la especificidad de cada construcción teórica sobre las prácticas de comunicación. Como contracara de cada especificidad de los lenguajes y las prácticas y en directa relación epistemológica, se encuentran las preguntas sobre los rasgos y procesos compartidos entre estas especificidades. Este es el proceso a través del cual las diferentes ciencias construyen un campo disciplinario común: una especie de zigzag entre las especificidades que guardan relación lógica y ontológica entre sí y la horizontalidad de diferentes campos, prácticas y tecnologías. La construcción y el desarrollo de un campo de conocimiento, una disciplina o una ciencia no pueden proseguir y crecer sino mediante el entrecruzamiento de su verticalidad con su horizontalidad.

En la construcción de conocimiento sobre la comunicación, estos procesos transversales se han visto obstaculizados, cuando no impedidos por varias razones: por un lado, una multiplicidad de abordajes teóricos muchas veces incongruentes entre sí y una discusión interminable sobre la especificidad de la comunicación abordada como lenguaje, como prác-

10 Es en este sentido que pienso productiva la búsqueda dialógica entre teorías de orígenes diferentes, a fin de construir un abordaje topológico-ontológico para los estudios de comunicación. Las TIC han construido una nueva ecología de la comunicación y, posiblemente, la construcción de metáforas sea una estrategia útil para pensarlas como procesos situados, material, cultural y antropológicamente. Asimismo, la noción de referenciación alude al poder de la semiosis humana para crear —o exteriorizar- en objetos externos procesos psíquicos internos. 
tica social o como cultura (tres dominios centrales reconocidos como relevantes y propios de la comunicación); por otro, la increíble velocidad y multiplicación de tecnologías, soportes y prácticas de información y de comunicación. La identidad específica de una ciencia del sentido parece diluirse y confundirse con la multiplicación de los soportes y las prácticas que crecen de manera exponencial. Las diferentes teorías que pretendieron dar cuenta de su especificidad propia quedan rápidamente superadas y obsoletas. Así es como entendemos las dificultades que han surgido para construir conocimiento sobre los procesos de la mediatización social y la aparición de nuevos lenguajes y relaciones entre múltiples medios de infocomunicación que operan sobre diferentes plataformas y soportes mediáticos. La semiosis del lenguaje o la lectura desarrollados a partir de De Sausurre o la semiosis de Peirce sufren procesos de replanteo permanente, donde este último parece conservar mayor poder de análisis que el primero sobre los procesos de indicialidad que marcan la mediatización creciente de nuestras sociedades. Ya no solo de los lenguajes y los medios, sino de la vida social concreta con las tecnologías digitales a través de la conexión permanente (connectedness), como señala la literatura sobre las redes sociales y los sistemas de vigilancia y control. ${ }^{11}$

En síntesis, podemos decir que — lamentablemente - la "verticalidad" del campo queda subsumida en la velocidad y la multiplicación de sus procesos de horizontalidad. La omnipresencia de la tecnología como significante termina "deconstruyendo" cualquier significación valedera o trascendente. Y en relación con esta metáfora, agreguemos que la construcción teórica de un campo de la comunicación en cuanto construcción epistemológica se ve obligada a redefinirse ontológicamente de manera constante. Durante siglos, el libro y la lectura sentaron un paradigma que parecía permanente y estable: texto, soporte del texto, lector y lenguaje. Con la invasión de las nuevas tecnologías y dispositivos de información y comunicación digitales, ya no se trata solo de la multiplicación y las transformaciones de los soportes y las pantallas omnipresentes en absolutamente todos los órdenes

11 "Las TIC realmente están en todos lados, no solo nos rodean, sino que además penetran nuestra intimidad: pueden ver, oír y registrar casi todo, sino todo, y parecen querer reemplazar la omnipresencia divina por la magia negra de la tecnología” (Vizer y Carvalho, 2014, p. 285). 
de la vida social. No se trata solo de la producción de nuevas textualidades, sino de las complejísimas influencias y condicionalidades que se les imponen a los sentidos y a los procesos de percepción e interpretación para los nuevos "lectores". Se han modificado radicalmente los procesos de percepción, de atención, de relación entre los sentidos y los procesos cognitivos. Se han generado nuevas - y revolucionarias - espacialidades, nuevos órdenes de realidad y nuevas temporalidades, que han producido lo que podemos considerar una "emergencia ontológica" de nuevos contextos y ambientes para la vida humana, todo a merced de nuevas tecnologías y modalidades de referenciar al mundo, a los otros y a la cultura. Desde el punto de vista de la teoría de sistemas, diríamos que las TIC han hecho emerger nuevos entornos (y Umwelts) y nuevas topologías en las que se construyen hoy los sistemas sociales. Paralelamente, el ser humano se ha visto obligado a reconstruir de manera contante sus redes cognitivas, a realizar - consciente o inconscientemente - nuevas asociaciones mentales entre los sentidos y las lógicas de interpretación que le permitan generar cierto orden y sentido dentro del caos de permanentes estimulaciones perceptuales a lo que lo somete el bombardeo interminable de mensajes, estímulos e informaciones. A todos los cuales está obligado a filtrar, rechazar o procesar, a fin de sostener cierta "normalidad" en la reconstrucción de su mundo de la vida dentro de entornos cada día más inciertos e imprevisibles.

\section{¿Tendría sentido pensar una ontología o una topología de la comunicación? Líneas teóricas para el abordaje de la mediatización}

No es muy común asociar las reflexiones sobre la comunicación a una cuestión de naturaleza ontológica, ya que se tiende a confundir groseramente la noción de ontología con la cuestión de los dispositivos, los objetos empíricos o la técnica aplicada. La construcción de teorías de la comunicación pensando desde un abordaje de sus "materialidades", desde los mecanismos, procesos y dispositivos físicos que permiten la construcción de textos y contextos, y planteando los lenguajes en relación con los soportes que los sustentan físicamente, ayudaría a investigar las articulaciones entre esas materialidades y la construcción de mensajes. El desarrollo de 
estas investigaciones nos llevaría a concebir una ontología de la comunicación, donde los "contenidos" se interpretarían como una arquitectura simbólica a la que se referían tradicionalmente los estudios de comunicación, pero una arquitectura simbólica asentada en procesos extrasimbólicos que la hacen posible.

Por eso, una postura meramente empirista (sobre la radio, el cine, la televisión o los dispositivos digitales) oscurece la profundidad y complejidad de las implicaciones filosóficas y sociales que introducen las tecnologías en la vida de las sociedades. En la búsqueda por "desentrañar" lo comunicacional, el investigador brasileño José Luiz Braga indica:

Desentrañar lo comunicacional no corresponde a definir un "territorio" aparte, ni temas, objetos o métodos que nos sean exclusivos, sino desenvolver preguntas e hipótesis más allá de las que ya fueron hechas por las otras ciencias humanas y sociales; las que no harían porque sobrepasarían su ámbito de interés y las lógicas de su campo de conocimiento. (2011, p. 72)

El mismo investigador define la comunicación como un proceso que transforma lenguajes, códigos e instituciones sociales. Esta mirada amplía el ámbito de la comunicación más allá de los abordajes meramente semiológicos o culturalistas que constituyen una gran mayoría de los estudios que se realizan, de modo que el campo de la comunicación evidentemente excedería lo estrictamente semiótico, derivando sus inquietudes hacia preguntas sobre los orígenes y condicionantes materiales de las transformaciones sociales, culturales, semióticas y antropológicas. Luego, afirma:

El objeto de la comunicación no puede ser aprehendido en cuanto "cosas", ni "temas", sino como un cierto tipo de procesos epistémicamente caracterizados por una perspectiva comunicacional (nuestro esfuerzo es percibir procesos sociales en general bajo la óptica que busca en ellos la distinción del fenómeno — comunicacional-). (p. 66)

Lo relevante para este autor sería que nuestras conjeturas sean testadas por su capacidad para "explicitar procesos que se pretenden caracterizar como un 'fenómeno comunicacional'”. Yamamoto (2013) propone un cuadro esquemático de la comunicación de acuerdo con ese autor. 


\begin{tabular}{|c|c|}
\hline Naturaleza & Proceso instituyente \\
\hline Modelo & Comunicación = código + inferencias \\
\hline Objeto & Transformaciones sistémicas (lenguaje e instituciones) \\
\hline Método & Indiciario e inferencial \\
\hline
\end{tabular}

Fuente: Yamamoto (2013, p. 106).

El paradigma del espectáculo ha sido una marca identititaria para la era de los medios analógicos en la sociedad de masas del siglo XX. Debord (2000) comenzaba su obra La sociedad del espectáculo señalando que "toda la vida de las sociedades donde rigen las condiciones modernas de producción se manifiesta como una inmensa acumulación de espectáculos. Todo lo que antes se vivía directamente se aleja ahora en una representación” ( $\mathrm{p}$. 57). Esta era de la representación ya no responde al orden ontológico del siglo XXI al que corresponde un nuevo paradigma, mejor categorizado por la multiplicidad de topologías sociotécnicas, por infinidad de protocolos de información, por algoritmos matemáticos y por nuevas prácticas culturales y sociotécnicas; nuevas convergencias, desvíos y transformaciones en las tendencias de las configuraciones comunicativas. Estas configuraciones comunicativas han trastrocado la ecuación secuencial entre emisión y recepción, promoviendo a cualquier espectador a actor y a todo actor en espectador; "the show never stops, it always goes on, the show is yourself" (el show nunca se detiene, siempre prosigue, el show es usted mismo).

Tal vez convenga una construcción de teorías de la comunicación pensando en el abordaje de sus "materialidades", en los mecanismos, procesos y dispositivos que permiten la construcción de contextos, lenguajes y soportes que sustentan físicamente las articulaciones entre esas materialidades y la construcción de mensajes, donde los "contenidos" aluden a la mera arquitectura simbólica de la comunicación. Las materialidades reintroducen miradas sobre la comunicación desde una perspectiva ontológica.

En principio, se reconocen dos tradiciones de investigación: la institucionalista y la socioconstructivista; la primera orientada hacia los medios masivos con una influencia signada por la "lógica de los medios", y la segunda centrada en las prácticas de comunicación cotidianas, "especial- 
mente aquellas relacionadas con los medios digitales y la comunicación personal". Un objetivo central sería desarrollar un "cuadro teórico emergente de lógicas institucionales" (Hepp, 2014, p. 25). Este autor contrapone la tradición institucionalista a la socioconstructivista sosteniendo que "ambas concuerdan en que la mediatización es el concepto que capta la interrelación entre las mudanzas de los medios y de la comunicación y de la cultura y la sociedad” (p. 45). Finalmente, tenemos la postura de Verón (2014), que propone una perspectiva semioantropológica de larga duración sobre la mediatización, y sostiene que "los procesos mediáticos son una característica universal de todas las sociedades humanas” (p. 13).

Hepp (2014, p. 47) sostiene que la tradición socioconstructivista alude a la noción de configuración cognoscitiva. Sobre esta última noción, en "la configuración cognoscitiva del campo de la investigación académica de la comunicación”, el investigador mexicano Fuentes Navarro (1996, p. 243) menciona un estudio del que surgen los siguientes "marcos disciplinarios" que encuadran la investigación en comunicación: sociológicos, comunicacionales, históricos, educativos, antropológicos, epistemológico-metodológicos, económico-políticos, lingüístico-semióticos, entre otros.

Si los estudios sobre los primeros medios en el siglo XX requerían esta multiplicidad de abordajes, se hace obvia la dificultad señalada respecto de la transversalidad:

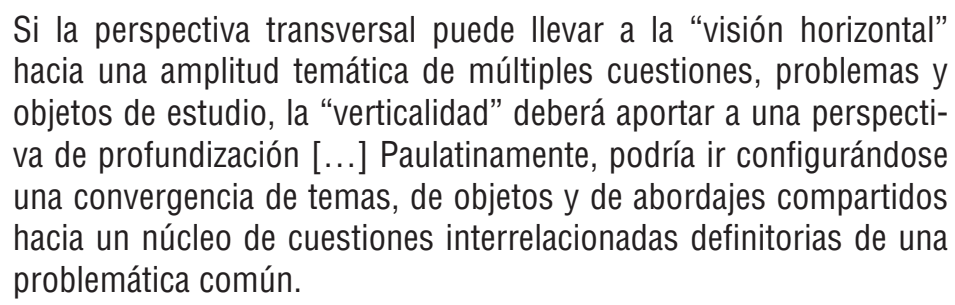

Y la noción de configuración cognoscitiva no solo es útil para trabajar sobre una epistemología de los estudios de comunicación, sino también sobre la influencia de los medios que operan sobre la configuración cognoscitiva de las mentes de los individuos en el campo real de tramas, actores, instituciones y lógicas compartidas de los hechos mediáticos. Un conjunto 
de procesos sistémicos que operan en cuanto topologías (o una incipiente ontología) de la esfera de la comunicación entre los medios, las instituciones, las mentes de los individuos y la cultura. Fuentes (1998) menciona que

la formulación de Vizer puede servir como descripción inicial del carácter cognoscitivo del estudio de la comunicación:

La comunicación define como propio un campo de problemas y de hechos, cuya característica es la multidisciplinaridad, las mediaciones y las articulaciones entre la fragmentación y la diversidad de lo que denominamos "realidad", y en primer lugar la caótica y compleja interdependencia de hechos, procesos y sistemas de la realidad social, que al "reflejarse" en los medios de comunicación a nivel global, tienden a reforzar en forma recursiva las tendencias tanto hacia la estabilidad como hacia el cambio, abriendo un horizonte de incertidumbre, complejidad creciente y cambio global. (p. 48)

Si bien esta formulación la realicé a comienzos de la década de 1990 pensando en los medios analógicos, creo que puede ser válida para reflexionar sobre la omnipresencia transversal y la interdependencia sistémica entre los medios, las organizaciones y los procesos de mediatización de nuestras sociedades. La figura actual de la sociedad en red y la multiplicidad e interdependencia global entre las instituciones, los actores sociales y las tecnologías de la información y la virtualidad no hacen sino profundizar la necesidad de abordar sus problemáticas desde perspectivas no reduccionistas ni estrictamente disciplinarias: la información y la comunicación constituyen en sí mismas la savia que realimenta y da sentido a todas las redes permanentemente. Para entender el funcionamiento y la supervivencia ontológica de este ecosistema, creo que permanece vigente

la necesidad de un "dispositivo" comunicacional transdisciplinario, ya que numerosas disciplinas han requerido — tanto por necesidad teórica como por ejercicio de su práctica- el "auxilio" de conceptos, modelos y abordajes comunicacionales (como la psicología, la economía, la sociología, la antropología y otras disciplinas). (Cervantes y Sánchez, 1994, p. 364)

Sostenía en esos años que una característica central que marcaba un rasgo específico para las teorías de la comunicación era su naturaleza re- 
cursiva: la conceptualización teórica de la comunicación como un metadiscurso (sobre los propios procesos de comunicación). Como reflexión sobre la necesidad de "un dispositivo teórico, un discurso sobre el sentido y sobre los propios discursos que construyen sentido (como en los procesos de comunicación dentro de los cuales construimos sentido en la vida cotidiana)” (Vizer, 1994, p367.). Esta postura nos acerca ahora muchísimo al pensamiento de Craig (1999) y a la necesidad de pensar como objetivo la construcción de una especie de matriz central que reúna problemas compartidos por las diversas disciplinas que "hablan de comunicación":

A pesar de que la teoría de la comunicación no es aún un campo
coherente (de conocimiento), creo que puede y deberá llegar a ser-
lo. Un campo va emerger en la medida en que nos comprometamos
como teóricos de la comunicación con objetivos socialmente im-
portantes, cuestiones y controversias que cruzan a través de varias
tradiciones disciplinarias, especialidades, metodologías y escuelas
de pensamiento que en el presente nos separan. Yo argumento que
todas las teorías de la comunicación son relevantes para un mundo
de la vida en que la comunicación ya es un término profundamente
significativo. La teoría de la comunicación es en este sentido un
campo coherente de práctica metadiscursiva, un campo del discur-
so sobre el discurso con implicaciones para la práctica de la comu-
nicación. (p. 120)

Por último, podemos decir que este escenario nos requiere teórica, crítica y epistemológicamente discutir y argumentar con las teorías de la complejidad (Edgar Morin y otros) y con Heinz von Foerster y la teoría de sistemas. También nos acerca al McLuhan de la visión ecológica de las tecnologías de los medios y demanda a Bruno Latour y la teoría del actor-red. Pero también deberemos remitirnos especialmente a Jacques Derrida y a Hans Ulrich Gumbrecht, así como a los autores que han trabajado sobre las materialidades de la comunicación. La hipermediatización universal nos sumerge en semióticas y entornos icónico-indiciales (icónicos como el cine, indiciales como la televisión). Y aquí es donde nos reencontramos curiosamente con Jacques Lacan y su propuesta de los tres registros de realidad: imaginario, simbólico y real. Estos pueden ser planteados también como registros de la comunicación y de los procesos de construcción de sentido. El sentido no puede operar o al menos hacerse inteligible sin la articulación 
entre los tres registros y las interfaces que se establecen entre ellos que hacen posible la interpretación. Esta es a la vez real (las condiciones de materialidad de un discurso), simbólica (los códigos del lenguaje) e imaginaria (la memoria, las metáforas, las imágenes que despierta un mensaje). Si entendemos la realidad cotidiana en el sentido de estos tres registros, la comunicación se presenta prácticamente como un proceso fundamental del que formamos parte activamente desde el propio nacimiento. Un proceso complejo y multidimensional en el que participamos desde antes de comenzar a hablar en la infancia, y dentro y a través del cual se forma y desarrolla la personalidad humana. Una verdadera ecología de la vida humana en comuni$d a d$. Una teoría de la comunicación no reduccionista se presenta como una perspectiva teórica indispensable sobre estas ecologías humanas. ${ }^{12}$

\section{La noción de referenciación y las tres dimensiones de creación topológica: una propuesta de modelización}

Como toda producción humana, los medios de comunicación existen y se mantienen porque su propia lógica de funcionamiento busca y desarrolla todas las posibilidades y soportes, todos los canales y registros que les permitan captar la atención de usuarios presentes o futuros, reales o imaginarios. En los cursos de comunicación, acostumbro a recalcar la importancia de la noción de referencia ${ }^{13}$ como una relación entre el lenguaje y un objeto externo a este. En segundo lugar, creo válido sostener que los mayores avances en comunicación se consiguen al establecer hipótesis de trabajo bidisciplinarias que refuerzan el argumento del refuerzo entre disciplinas

12 Tenemos un ejemplo de aplicación en la metodología de análisis de comunidades y organizaciones que hemos denominado socioanálisis comunicacional.

13 "Reference' for a philosopher, or for a linguist, is a relation between an element in a language, like the word John and something in the world (its 'referent'), such as the flesh-and-blood person John. One half of the relation is a bit of language; the other half of the relation is not. (For some philosophers, but not all, this relation is mediated by a psychological entity, a person's mental image, or concept, of the thing referred to)" (Referencia para un filósofo o para un lingüista es una relación entre un elemento en un lenguaje, como la palabra John y algo en el mundo (su referente), como la persona John de carne y sangre. La mitad de la relación es un poco de la lengua; la otra mitad de la relación no. Para algunos filósofos, pero no para todos, esta relación está mediada por una entidad psicológica, imagen mental de una persona o un concepto sobre el objeto que es referido) (Couldry, 2004, p. 83). 
que ayuden a relacionar procesos de comunicación con actividades y proposiciones de otras disciplinas, ya que los procesos semióticos de referenciación tienden a ser precisamente efectos o emergentes de actividades, contextos, situaciones o procesos muchas veces ajenos al ámbito semiótico, ámbitos que precisan del proceso semiótico, para realimentarse de información imprescindible y realizar su propia dinámica, desde organismos simples hasta los seres humanos.

En este sentido, asociando un proceso semiótico como el de referencia a un proceso ecológico, propongo tres dimensiones topológicas fundamentales que definen la especificidad semiótica de las prácticas de comunicación: una dimensión de referenciación como un proceso, una práctica o acción de establecer una relación entre el mundo objetual externo y un acto de lenguaje, una palabra, una frase, una imagen u otro objeto. Al mismo tiempo que esta relación es de naturaleza simbólica, o semiótica, se genera una acción de objetivación, de poner afuera, de "exteriorización de los procesos mentales en la forma de dispositivos materiales (los medios)” (Verón, 2014, p. 14). La asociación de la noción de referenciación con la hipótesis de la comunicación como construcción de realidad salta a la vista. Con esta asociación, también surge una hipótesis fuerte que sostiene que los procesos de referenciación, asociados a los objetos del mundo (que incluyen, obviamente, a otros humanos), tienden finalmente a construir una ontología real que emerge como consecuencia de la topología comunicacional del lenguaje, una topología (o topologías) de orden tanto real como simbólica e imaginaria. Surge, inmediatamente, una asociación epistemológica inevitable con la noción fenomenológica de mundos de la vida. Mundos donde las fronteras entre el afuera y el adentro y lo objetivo y lo subjetivo se relativizan y pierden la rigidez unívoca de un realismo estrechamente materialista. Es claro que investigar los procesos de comunicación y construcción de sentido desde estas perspectivas requiere nuevos abordajes teóricos y una concepción antropológica e histórica de la epistemología que sobrepasa los marcos disciplinarios de la lingüística, la sociología o de las ciencias cognitivas. Por ejemplo, Couldry (2004) observa la posición intermedia de los medios entre el polo económico y el cultural y afirma que esta posición le otorga un interés especial al análisis de los medios de comunicación como 
campo de investigación unitario, y propone como encuadre de análisis la aplicación de la teoría del campo planteada por Bourdieu.

There is little doubt that, as a sphere of cultural production, the media can prima facie be analysed as a single field, or a collection of fields, (each) with a distinctive pattern of prestige and status, its own values. Indeed, according to Bourdieu, the media's intermediate position between the cultural and economic poles of the wider cultural field gives it a particular interest as a field. This section notes the positive contribution of field theory to media analysis. ${ }^{14}$ (p. 677)

Una segunda dimensión que menciono es la interreferenciación, o sea, la necesidad de establecer y mantener vínculos con el otro (una relación mutua entre seres vivos o semejantes, los que, al referenciarse y objetivarse mutuamente, en una interacción de coconstrucción de relaciones, hacen emerger un contexto topológico común y compartido, un vínculo y un espacio específicamente "social"). Por último, propongo la dimensión de autorreferenciación (Vizer, 2003, 2007b, 2012) como la práctica semiótica de exteriorización y de reconocimiento de la identidad (individuo, grupo, institución o colectivo social) que pone en evidencia la propia existencia como entidad-identidad individual ante los otros, ante el mundo y ante sí mismo. Es en esta dimensión de la autorreferencia donde la presencia, las palabras y los gestos del sujeto (emisor individual o colectivo, voluntario o involuntario) reflexivamente coinciden con el propio sujeto comunicante (se torna un objeto de su propia habla, hace referencia a sí mismo, sea que lo haga de manera explícita o no). Con su sola presencia, el sujeto u actor social — aun antes de hablar — genera un espacio, una topología, que lo pone en evidencia (por eso la escuela de Palo Alto decía que es imposible no comunicar), y ese acto de "hablar" lo instituye ante el mundo como una identidad, como sujeto existente y real ante los otros y el mundo. Una topología de la identidad, una presencia que construye un efec-

14 Hay pocas dudas de que como una esfera de producción cultural los medios pueden prima facie ser analizados como un único campo o una colección de campos, cada uno con un patrón distintivo de prestigio, estatus y valores propios. Más aún, de acuerdo con Bourdieu, la posición intermedia de los medios entre los polos cultural y el económico en un campo cultural mayor le otorga un interés particular como campo. Se observa la contribución positiva de la teoría del campo al análisis de los medios de comunicación. (cita traducida por el autor) 
to de sentido, efecto expresable en palabras, gestos, imágenes, tonos de voz, presencia física o vestimenta.

Estas tres dimensiones requieren concentrar nuestra atención:

- En una práctica topológica de referenciación, una exteriorización o la producción objetiva de objetos de sentido o contextos (a través de un texto, una conducta, una charla, una imagen, un evento organizado o un acontecimiento, hasta llegar, finalmente, a una construcción cultural organizada en la forma de institución, etc.). En otras palabras, una especie de topología o una economía semiótica de producción de signos y significados (una expresión de la "construcción social de la realidad").

- Una práctica de construcción de una topología de redes y relaciones entre seres humanos, a fin de conseguir y mantener el establecimiento de lazos sociales. Las redes sociales (como interreferenciación social) representan un ejemplo relevante, por un lado, como modalidad de prácticas concretas (o virtuales) de creación de vínculos; y por otro, como un ejemplo concreto de topología emergente (como en el caso, en general, conflictivo de la política, ya sea instituida y organizada formalmente - como organismos de Estado-, ya sea instituyente como en los movimientos de protesta o de masas-). Estas relaciones interreferenciales también se manifiestan empíricamente como un espacio de prácticas sociotécnicas (como en la economía, los modos y las prácticas de producción y las tecnologías). Estos procesos sociales y técnicos en red son ampliamente investigados con metodologías sumamente precisas elaboradas originalmente en la Segunda Guerra Mundial por los matemáticos húngaros Paul Erdős y Alfréd Rényi que han dado origen a nuevas técnicas de estudio de redes sociales.

- Por último, la actividad comunicativa que todo sujeto o actor social realiza de manera implícita o explícita, en principio para afirmar la propia identidad o llamar la atención sobre la persona, desde individuos a empresas, clubes de fútbol o agencias de gobierno hasta entidades internacionales. Las prácticas autorreferenciales contribuyen al reconocimiento social, a la afirmación de la identidad y al ejercicio 
de la expresión personal. Todos necesarios para conseguir la atención del otro sobre uno mismo, sobre la propia identidad (se trate de un individuo, de una institución, una etnia, una comunidad o un país, a través del trabajo que realiza el actor social a fin de generar un capital propio por medio del aumento de la atención de los otros sobre sí, planteado así según Bourdieu-Couldry). Creo que las tres funciones o dimensiones de la comunicación permiten hallar un nexo fuerte, por un lado, entre los procesos semióticos como procesos mentales; y por otro, con la acción corporal y social, con las prácticas de la vida cotidiana. Y así también se establecen relaciones con los ambientes topológicos en que se desarrolla la vida que llamamos social: el ambiente físico, el social y el simbólico-cultural. Esta perspectiva permite quebrar la separación entre lo mental y lo físico como entidades totalmente dicotómicas e irreductibles entre sí y abordar los procesos de comunicación como conjuntos de una ontología a un mismo tiempo semiótica y físico-material (en buena medida, creo que la teoría del actor-red persigue un objetivo similar).

La referenciación, la exteriorización y la atención son funciones primordiales del acto de comunicación, ya sea en la interpersonal, ya sea en la mediada técnicamente. La influencia universal de los dispositivos tecnológicos de información y de comunicación ha profundizado y complejizado los procesos de emergencia de la mediatización social hasta un nivel nunca imaginado hace pocos años atrás, llevando las dimensiones de la comunicación mencionadas hasta lo que podemos denominar una crisis de escala que presenta una configuración inédita y planetaria para todas las sociedades. Antropológicamente, podemos afirmar que las sociedades humanas acrecientan permanentemente su capacidad para producir y procesar capital de referenciación ${ }^{15}$ o cultura, de una forma equivalente a la que se realiza a través de la economía en cuanto producción material, aunque las TIC han permitido la creación de procesos híbridos entre la naturaleza, la cultura y lo que se denomina economía inmaterial o cognitiva. Se produce un crecimiento ilimitado de la capacidad de producción no solo material, sino sim-

15 En este sentido, se presenta como interesante, y seguramente fructífera, la proposición que hace Couldry sobre la cultura como un metacapital, una noción que adapta a partir de la de capital, originalmente propuesta por Bourdieu. 
bólica, cultural y de conocimiento a través de las tecnologías, los bancos de datos, las redes de colaboración científica, etc. Por otro lado, la interreferenciación social mediante redes y dispositivos específicos y las experiencias compartidas (amén de la conectividad permanente) ha llevado al extremo la interdependencia mutua entre individuos, grupos, organizaciones y países (p. ej. la mundialización o la globalización). Aunque no se puede afirmar que estos crecimientos cuantitativos en la capacidad de conexión representen también un salto en la calidad de la interreferenciación, sí podemos pensar en el ámbito de la política como un emergente histórico del desarrollo cuantitativo y cualitativo de los procesos semióticos de interreferenciación que realimentan la construcción de los procesos, las estructuras y las dinámicas políticas (p. ej. la emergencia y formación de las instituciones políticas). Por último, la dimensión de la autorreferenciación, entendida como potencialidad de autonomía y expresión por parte del propio individuo, una etnia o un grupo, se ha fortalecido exponencialmente con la enorme multiplicación de dispositivos técnicos de comunicación; y a un nivel macrosocial podemos establecer paralelos con los procesos de creación de identidades colectivas e instituciones sociales. Por ejemplo, la publicidad y la propaganda son una manifestación moderna de un simulacro de autorreferencia, por el uso mediático de dispositivos y mensajes que construyen, difunden y buscan institucionalizar la imagen de una empresa, un producto, un partido político, una ideología, una institución y hasta un país.

En la evolución histórica de las sociedades, observamos la emergencia, la competencia y lucha entre identidades institucionales que plantean de manera implícita o bien explícita su propia autorreferencia y aun la búsqueda por la consolidación de una hegemonía entendida como valor universal, además de la diferenciación o distinción ante el resto de la sociedad. Tenemos así las figuras y representaciones del Estado y el Gobierno, del sistema judicial, religioso, educacional, productivo, de salud, etc. La modernidad europea implicó precisamente el reconocimiento de una autonomía identitaria por parte de instituciones que históricamente solo habían representado un apéndice del poder religioso o del sistema de gobierno, teniendo como ejemplos la Edad Media europea o las teocracias de la actualidad, en especial en el mundo islámico, donde el propio Estado se halla sujeto y su- 
peditado a la identidad y los valores de la religión como institución suprema. El comunismo chino o ruso del siglo XX reemplazaron la institución religiosa por una entidad intelectual ideológica y retrotrajeron la historia a una realización ideológica del racionalismo de los ideales del Iluminismo, suerte de monoteísmo intelectual ateo sustentado en la identidad autorreferente del partido y el Estado. Y con perdón del lector, creo que no sería exagerado sostener que en Occidente en el siglo XXI estamos viviendo un proceso que podríamos denominar con cierto humor monoteísmo de mercado, donde el valor central de referencia se halla sustentado en las identidades de las instituciones y las prácticas financieras más que en las específicamente económicas.

Así, no creo que se exagere cuando se habla de que nos hallamos ante la emergencia de nuevas modalidades civilizatorias. Una emergencia que no permite hablar —al menos en el presente- de evolución. En primer lugar, porque la noción de evolución se refiere a largos periodos, y luego porque habría que definir qué se entiende por el término. Creo más adecuado pensar según la emergencia de nuevas y más complejas formas de organización social y nuevas modalidades de establecimiento de lazos institucionales y sociales a través de la tecnificación tanto de la economía productiva como de la política, la gobernabilidad y el control social. También podemos referirnos a la emergencia y el crecimiento del acervo de conocimientos y experiencias registrados por las comunidades humanas, o sea, el aumento del stock de reservas de información y conocimiento comunicables, paralelamente al crecimiento de la capacidad para procesar enormes masas de información gracias a los propios medios infocomunicacionales (un crecimiento de la capacidad de referenciación). Con respecto a nuestra tercera dimensión, o sea, la autorreferenciación, se han venido planteando argumentos tanto optimistas (crecimiento de la autonomía y la autorrealización del individuo y de las comunidades enteras a través de la ampliación de las posibilidades de desarrollo personal) como argumentos más pesimistas sobre la dependencia creciente de las máquinas para realizar tareas tanto físicas como mentales (sobre todo a merced de las tecnologías virtuales y la inteligencia artificial). 
Cuando se lee o se escribe sobre los procesos de mediatización social, se hace referencia implícita - a veces explícita - al cambio tecnológico. Cuando este es asimilado por la sociedad y es institucionalizado estableciendo nuevos patrones de producción, podemos comenzar a considerar que nos hallamos frente a una emergencia o hasta una evolución temporal respecto de formas anteriores. Surgen nuevas formas de subjetividad, o lo que llamaré nuevas topologías de la subjetividad. Una nueva ontología de los mundos de la vida en la posmodernidad donde las TIC instalan nuevas prácticas que reconfiguran el rol (antes pasivo) de los individuos y las comunidades, que contribuye al mismo tiempo a generar la emergencia de una individualidad y una subjetividad activa, expresiva, conectada, a la vez material, virtual y colectiva. En este sentido, la sociedad industrial ha dado origen a los modos de producción actuales en la forma de una emergencia social de nuevas formas de producción sociotécnica, en las cuales la producción inmaterial (comúnmente llamada economía cognitiva) se alimenta, sobre todo, a través de operaciones semióticas que realimentan los procesos de producción y circulación de valores y objetos de información. Por último, debemos mencionar que el capital cultural de información y conocimiento (podemos llamarlo metacapital, según Couldry) tiende a crecer y circular indefinidamente, y es cada vez más incorporado a las prácticas económicas, sociales y culturales que dan origen a lo que hace unos años atrás denominábamos en las publicaciones especializadas sociedad mediatizada, diferenciándola así del rótulo ya clásico de sociedad de la información o de la comunicación. El campo de los estudios de la comunicación ganaría así una amplitud y densidad interpretativa en una escala y una profundidad ontológica nuevas. Por ejemplo, los procesos de circulación de la información y la comunicación ya no representarían una ausencia de productividad (como en la producción física clásica), sino la emergencia creciente de recursos productivos de carácter infocomunicacional y cultural emergentes de la propia circulación, e imprescindibles para nuevas formas

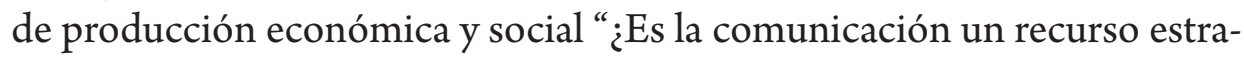
tégico para los productos digitales?” (Vizer, 2015). 


\section{Referencias}

Barábasi, A. L. (2009). Linked: a nova ciência dos networks. São Paulo: Leopardo.

Berger, P. y Lukmann T. (1968). La construcción social de la realidad. Buenos Aires: Amorrortu.

Braga, J. L. (2011). Constituição do campo da comunicação. Verso e reverso, $25(58), 62-77$.

Charaudeau, P. (1997). Le discours d'information médiatique: la construction du miroir social. París: Nathan.

Couldry, N. (2004). Media meta-capital: Extending the range of Bourdieu's field theory. En D. L. Swartz y V. L. Zolberg (eds.), After bourdieu (pp. 165-189). Dordrecht: Springer.

Craig, R. T. (1999). Communication theory as a field. Communication Theory, 9(2), 119-161.

Deleuze, G \& Guattari, F (1997). Mil mesetas. Capitalismo y esquizofrenia. Valencia: pre textos; 1-15.

Debord, G (2000). La sociedad del espectáculo. Valencia : Pre textos

Felinto, E. (2006). Passeando no labirinto: ensaios sobre as tecnologias e as materialidades da comunicação. Porto Alegre: EDIPUCRS.

Fuentes Navarro, R. (1998). La investigación académica de la comunicación en México: notas para un balance reflexivo. Estudios sobre las Culturas Contemporáneas, 4(8), 35-59.

Giddens, A. (1987). Las nuevas reglas del método sociológico. Buenos Aires: Amorrortu. 
Gorz, A. (2003). L'immatériel: connaissance, valeur et capital. París: Galilée.

Gumbrecht, H. U. y Pfeiffer, K. L. (1988). Materialities of communication. Palo Alto, CA: Stanford University Press.

Hepp, A. (2014). As configurações comunicativas de mundos midiatizados: pesquisa da midiatização na era da "mediação de tudo". Matrizes, 8(1), 45-64.

Hjarvard, S. (2014). Midiatização: conceituando a mudança social e cultural. Matrizes, 8(1), 21-44.

Kuhn, T. S. (1970). The structure of scientific revolutions (2. ${ }^{\mathrm{a}}$ ed.). Chicago: University of Chicago Press.

Lacan, J. (2007). El Seminario de Jacques Lacan Libro 11: Los cuatro conceptos fundamentales del psicoanálisis, 1964. Buenos Aires: Paidós.

Lash, S. y Urry, J. (eds.) (1998). Economías de signos y espacio: sobre el capitalismo de la posorganización. Buenos Aires: Amorrortu.

Latour, B. (2005). Reassembling the social: An introduction to actor-networktheory. Oxford: Oxford University Press.

Lazzarato, M. y Negri, A. (2001). Trabalho imaterial, formas de vida e produçao de subjetividade. Río de Janeiro: DP\&A.

Lenoir, T. (1998). Inscribing science: Scientific texts and the materiality of communication. Stanford, CA: Stanford University Press.

Lévy, P. (2014). A esfera semántica: computaçao, cognição, economia da informação. São Paulo: Annablume.

Logan, R. (2012). Que é informaçao? A propagaçao da organização na biosfera, na simbolosfera, na tecnosfera e na econosfera. Río de Janeiro: Pontifícia Universidade Católica do Rio de Janeiro. 
Kuhn, T. (1962). A estrutura das revoluções científicas (5. a ed.). São Paulo: Editora Perspectiva.

Martin-Barbero, J. (1987). Dos meios as mediações: comunicaçao, cultura e hegemonia. Río de Janeiro: Universidade Federal do Rio de Janeiro.

Moutier-Boutang, Y. (2007). A bioproduçao: o capitalismo cognitivo produz conhecimentos por meio de conhecimento e vida por meio de vida. IHU Online, 216. Recuperado de http://www.ihuonline. unisinos.br/artigo/858-yann-moulier-boutang-1

Perzanowskis, J. (2011). In search of ontological conditions for emergence. En J. Sytnik-Czetwertyński (ed.), Art of philosophy: A selection of Jerzy Perzanowski's Works (pp. 121-134). Frankfurt: Ontos Verlag.

Peirce, C. S. (1999). Semiótica: estudos (2. ${ }^{\mathrm{a}}$ ed., trad. J. Teixeira Coelho Neto,). São Paulo: Perspectiva.

Popper, K. (1993). A lógica da pesquisa científica. São Paulo, Cultrix.

Saad Corrêa, E. (2015). Centrality, transversality and resiliency: Thoughts on three digital contemporary conditions and Communication epistemo$\log y$. Ponencia presentada en Congreso Internacional de IBERCOM, São Paulo.

Saussure, F. de (2008). Curso de linguística geral. São Paulo: Editora Cultrix.

Sohn-Rethel, A. (1976). Intellectual and manual labour: A critique of epistemology. Londres: Macmillan.

Strate, L. (2010). Korzybski, Luhmann, and McLuhan. Proceedings of the Media Ecology Association, 11, 31-42.

Verón, E. (2014). Teoria da midiatização: uma perspectiva semioantropológica e algumas de suas consequências. Matrizes, 8(1), 13-19. 
Viana, N. (2011). Debord: espetáculo, fetichismo e abstratificação. Panorama, 1(1), 5-14.

Vidales Gonzáles, C. E. y Vizer, E. A. (coords.) (2016). Comunicación, campo(s), teorías y problemas: ona perspectiva internacional. Sevilla: Comunicación Social.

Vizer, E. A. (1994). El modelo actor-observador y el desarrollo de una perspectiva comunicacional. En C. Cervantes Barba y E. E. Sánchez Ruiz (coords.), Investigar la comunicación: propuestas iberoamericanas (pp. 366-392). Guadalajara, México: Universidad de Guadalajara, 367.

Vizer, E. A. (2003). La trama (in) visible de la vida social: comunicación, sentido y realidad (2a. ed.). Buenos Aires: La Crujía.

Vizer, E. (2007a). Interfases y líneas de investigación entre procesos sociales y procesos de comunicación. En J. Ferreira (ed.), Cenários, teorías e epistemologías da comunicação (pp. 189-209). Río de Janeiro: e-papers.

Vizer, E. A. (2007b). Procesos sociotécnicos y mediatización en la cultura tecnológica. En D. de Moaes (coord.), Sociedad mediatizada (pp. 39-68). Barcelona: Gedisa.

Vizer, E. A. (2008). Midiatização e (trans) subjetividade na cultura tecnológica-a dupla face da sociedade midiatizada. En Midiatização e processos sociais na América Latina (pp. 31-50). São Paulo: Paulus.

Vizer, E. A. (2012). Comunicación y socioanálisis: estrategias de investigación e intervención social. Madrid: Editorial Académica Española.

Vizer, E. A. (2015). Cuerpos mediatizados: sobre el estatuto de los cuerpos a partir de la modernidad. En S. Calero Cruz, C. C. Rivera Gómez y P. A. Restrepo Hoyos (comps.), Cuerpo y comunicación (pp. 357-391). Cali, Colombia: Universidad Autónoma de Occidente. 
Vizer, E. A. y Carvalho, H. (2015). La perspectiva ecológica y la hipermediatización social. Palabra Clave, 18(4), 1087-1110.

Vizer, E. A. y Carvalho, H. (2013). Socioanalysis: A communicational research device for social intervention. Historical Social Research, $38(2), 218-235$.

Vizer, E. A. y Carvalho, H. (2014). El ojo de Dios: conectados y vigilados. Los medios como ecología del poder. En E. A. Vizer (coord.), Lo que McLuhan no predijo (pp. 173-187). Buenos Aires: La Crujía.

Vizer, E. A. y Carvalho, H. (2015). Is communication a strategic resource for digital commodities? E a comunicação um recurso estratégico para as mercancías digitais? Revista Extraprensa, 9(1), 102-113.

Vizer, E. A. (coord.) (2016). Comunicación, campo(s), teorías y problemas: una perspectiva internacional. Salamanca: Comunicación Social.

Wallerstein, I. (1996). Abrir las ciencias sociales. México: Siglo XXI.

Yamamoto, E. Y. (2013). Desentranhar o comunicacional: a comunicação segundo José Luiz Braga. Questões Transversais-Revista de Epistemologias da Comunicação, 1(2). 